\title{
@realDonaldTrump: political celebrity, authenticity, and para-social engagement on Twitter
}

\author{
Andrea McDonnell and Mark Wheeler
}

\begin{abstract}
QUERY SHEET
This page lists questions we have about your paper. The numbers displayed at left are hyperlinked to the location of the query in your paper.

The title and author names are listed on this sheet as they will be published, both on your paper and on the Table of Contents. Please review and ensure the information is correct and advise us if any changes need to be made. In addition, please review your paper as a whole for typographical and essential corrections.

Your PDF proof has been enabled so that you can comment on the proof directly using Adobe Acrobat. For further information on marking corrections using Acrobat, please visit http://journalauthors.tandf.co.uk/production/acrobat.asp; https://authorservices.taylorandfrancis.com/how-to-correct-proofs-with-adobe/
\end{abstract}

The CrossRef database (www.crossref.org/) has been used to validate the references. Changes resulting from mismatches are tracked in red font.

\section{AUTHOR QUERIES}

Q1 Please provide missing Department for the affiliation.

Q2 Please provide missing Department for the affiliatio

Q3 Please provide an abstract of up to 200 words for the article, if need

Q4 Please provide 3 to 5 keywords for the article, if needeo

Q5 The reference "Weber 1946" is cited in the text but is not IIsted in the references list. Please either delete in-text citation or provide full reference details following journal style [X Harvard

Q6 The disclosure statement nas been inserted. Please correct if this is inaccurate.

Q7 The CrossRef database (www.crossref.org/) has been used to validate the references. Mismatches between the original manuscript and CrossRef are tracked in red font. Please provide a revision if the change is incorrect. Do not comment on correct changes.

Q8 Please provide missing page number for the "Street, 2003" references list ent

Q9 Please provide missing page number for the "Weber, 1998" refereprog list entry.

Q10 The reference "Weber et al., 1998" is listed in the references list but Ts not cited in the text. Please either cite the reference or remove it from the references




FORUM

\title{
@realDonaldTrump: political celebrity, authenticity, and para-social engagement on Twitter
}

\author{
Andrea McDonnell ${ }^{\mathrm{a}}$ and Mark Wheeler ${ }^{\mathrm{b}}$ \\ aEmmanuel College, Boston, USA; 'bondon Metropolitan University, London, UK \\ ARTICLE HISTORY Received 1 February 2017; Accepted 13 August 2018
}

\section{Introduction}

The celebrity politician is no longer an exceptional type of political actor, but a vital and identifiable figure in modern culture, one who has a profound impact on political practice and participation in the twenty-first century (Street 2003, 2004, 2010). With the rapid development and adoption of digital technologies, namely web-based and social media platforms, celebrity candidates have deployed new strategies for attracting and communicating with constituents and enhancing their political capital. These platforms also allow politicians to present a version of themselves that appears unmediated, personal, and authentic (Wheeler 2014). Throughout his 2016 U.S. Presidential campaign, Donald Trump used social media, most notably Twitter, to communicate with voters; by Election Day, he had 13 million followers on the site. ${ }^{1}$ Trump's proclivity for posting seemingly off-the-cuff remarks transformed his 140-character-or-less comments into major news stories, often shaping media coverage of the candidate and his campaign.

As Goffman writes in his seminal (1959) study, The Presentation of Self in Everyday Life, in order for an actor's behaviour to become meaningful to others, 'he must mobilize his activity so that it will express during the interaction what he wishes to convey' $(1959$, p. 30); it is this mobilization that Goffman calls dramatic realization. Thanks to an increasingly diverse and fragmented media landscape, the opportunities, and challenges, of dramatic realization are ever expanding. Public figures now perpetually perform, both within and outside of the 24 $\mathrm{h}$ cable news cycle. It has become de rigueur for celebrities and political actors to dram cally realize the version of self whom they wish the public to know via social media platforms. Thus, the private self that Goffman describes as existing backstage has been supplanted by a constant performativity in which the 'real' self is publically enacted. Meyrowitz (1986) calls this activity side stage behaviour, and it represents yet another layer of performative showmanship. In our twenty-first century, media-saturated political landscape, it may well be, then, that a candidate's ability to dramatically realize a political persona has become more important than his or her experience or ability to govern.

Social media platforms help politicians to establish and maintain their political brand and to attract supporters. Throughout his campaign, and into his presidency, Donald Trump's Twitter use has effectively enhanced his charismatic authority. As defined by the sociologist Max Weber, charismatic authority is a kind of power and influence that rests on the

CONTACT Andrea McDonnell mcdonnella@emmanuel.edu

๑) 2019 Informa UK Limited, trading as Taylor \& Francis Group 
individual's ability to continuously 'prove' his legitimacy, determination, and strength in ways that compel followers to 'faithfully surrender' to him (Weber 19arp. 78). For Trump, Twitter provides a platform for the ongoing performance of charismat thority. On social media, authority is no longer dependent on law or tradition, nor on the individual's ability to embody democratic norms and values, nor on expertise. Rather, it is one's ability to present oneself as exceptional and authentic that draws followers.

Online, traditional modes of political communication - the vocal, the physical, and the rhetorical - become enmeshed with the iconic, the hypertextual, and the virtual. Candidates command credibility through a conjunction of de-institutionalisation, personalisation and para-social familiarity. Para-social interaction (PSI) occurs when an individual interacts with a media figure as though that figure were a person whom the individual personally knows in everyday life (Horton and Richard Wohl 1956). Social media platforms foster para-social engagement via users' direct interaction in the form of comments, likes, retweets, and the exchange of messages, photos, and videos. These functions, combined with the fact that social media platforms do not distinguish between celebrities, politicians, and real-world associates (online, these are all simply 'friends' or 'followers') foster a sense that public figures are available and knowable.

Whether celebrities and politicians post on social media themselves or hire a team to manage these interactions is debatable. Nevertheless, the proliferation and ubiquity of digital, social modes of interaction herald significant changes in the affective capacities of public figures (Marshall 1997). These changes have shaped the ways in which the public thinks about and interacts with politicians, particularly populist figures (Marsh et al. 2010, Wheeler 2013). By analysing Donald Trump's use of Twitter during his U.S. Presidential campaign, we seek to better understand how political celebrities use social platforms to connect with followers and to enhance their authority and celebrity.

\section{Method}

According to the Wall Street Journal Twitter tracker, Trump averaged 11 tweets per day via his @realDonald Trump handle over the course of his campaign, tweeting a total of 35,244 times between January 2015 and early November $2016 .^{2}$ This study considers tweets posted during the 28 days leading up to the 2016 Presidential election, including content posted between midnight October 11 and 11:29 pm 7 November 2016. During this period, Trump tweeted 440 times, with 429 original posts and 11 retweets. We examine the rhetorical, thematic, and visual strategies of these posts and inductively identify recurring motifs.

\section{Findings}

Trump's twitter handle, @realDonaldTrump, conveys a sense of legitimacy and authenticity; it seems to say, 'don't be fooled by imitations'. His profile photo, a closely cropped headshot shows Trump in natural lighting, eyes to camera, looking directly out at the viewer. Though Trump has acknowledged that aides do at times post on his behalf - at one point, he tweeted that he had turned his account over to his 'team of deplorables' - alerts such as these reinforce an assumption that all other tweets are authored by the candidate himself. Combined, these profiles features assure followers that they are privy to Trump's genuine and unfiltered thoughts. 
In tweets, Trump's use of language fosters a sense of immediacy and connection with followers. He regularly employs first-person address, referring to himself as 'I' and audiences as 'you'. He often posts to thanks his supporters, as in an October 19 tweet in which he writes, 'Great poll - thank you America!' Trump also employs words such as 'together' and 'we', which suggest a shared responsibility and interaction: 'We have all got to come together and win this election' (10/17). He directly hails readers, referencing voters in different states, by sending targeted messages: 'Thank you for your support Greensboro, North Carolina' (10/14) and 'Thank you Las Vegas, Nevada - I love you!' (10/30). These posts encourage PSI with followers while reinforcing a sense that his social media posts are candid and personal.

But perhaps the strategy that Trump relies on most frequently is that of identifying instances of insincerity as he sees them. Many of his posts are accusatory and he condemns everyone from reporters and media outlets, to former employees, to his opponent as 'crooked', 'made up', 'biased', and 'corrupt'. His tweets accuse the media - and the election process itself - of being 'rigged', telling followers, 'don't let them fool you' (10/11; 10/24). A favourite hashtag, \#BigLeagueTruth, supposedly alerts readers to instances in which Trump reveals or uncovers the 'real story' that he alleges is being hidden from the public. For instance, on October 10 Trump tweets, 'Wow, @CNN got caught fixing their "focus group" in order to make Crooked Hillary look better. Really pathetic and totally dishonest!' The exclamatory tone reinforces Trump's image as a straight-talker while branding Cable News Network (CNN) and Clinton as untrustworthy 'frauds'.

Trump's favoured moniker for Democratic opponent Hillary Clinton is 'Crooked Hillary', a nickname that marks her as being inauthentic and insincere. Trump's rhetorical branding of Clinton is emphasized most notably on October 19, the date of the third and final presidential debate, on which he logs his highest number of posts to date: 87 . In 22 posts, he directly criticizes Clinton, claiming the state department worked 'illegally' for her and that the Clinton foundation is a 'CRIMINAL ENTERPRISE!' Trump also tweets that Clinton has 'no credibility' and that 'no secretary of state has been more wrong, more often, and in more places'. At times, Trump stops short of using Clinton's name, simply referring to her as Crooked: 'Crooked's top aides were MIRED in massive conflicts of interest'.

Trump's tweets also include visual cues that reinforced his rhetoric. Another debate-day post, in which Trump tweets, '\#CrookedHillary is no more than a Wall Street PUPPET!' is accompanied by a video of cartoon Clinton dangling from marionette strings. A similar video post includes a gif of Hillary's first name in white font, with the letters spelling 'liar' highlighted in red; the visual cue suggests liar is literally part of who Hillary Clinton is (10/19). In another post, Trump tweets an unflattering black and white photo of Clinton superimposed with a quote: 'Hillary is the most corrupt person to ever run for the presidency of the United States' (10/18). The words 'most corrupt person' are highlighted by a red band. The author of the quote, cited in the post, is Trump himself. Thus, while he claims to reveal truths and speak honestly, Trump's strategy for bolstering his authority and authenticity is not primarily rooted in the delivery of information, but in his unceasing undercutting of his opponents.

\section{Discussion and conclusions}

Donald Trump's use of Twitter proved to be a successful tool for political communication throughout the 2016 election campaign. His social media performativity and dramatic 
realization of an outsider candidate helped Trump effectively appeaco a significant portion of the electorate in key battleground states who, on November 2016 , propelled him to the White House. Now, three years into his presidency, Twitter has remained Trump's favoured platform for communication.

Since, his inauguration Trump has continued to use Twitter to foster para-social relations with his base and cast himself as an anti-establishment foil to the establishment political class and the mainstream media. As president, Trump tweets to connect with supporters, test policy propositions, obfuscate his decision-making, damn his political opponents (both within and without the White House), and to even fire highranking cabinet officials. All the while, his social media presence has continued to grow; Trump has more than 25 million followers on his @realDonaldTrump handle and another 22.5 million followers on the official @POTUS account, from which he also tweets. In sum, Trump has successfully used Twitter to dramatically realize his maverick appeal, to enhance his charismatic authority, and to reinforce his claims on unfiltered authenticity (i.e. lack of 'political correctness'). He has also bolstered his fame and celebrity brand, a fact Trump himself acknowledged in a March 6 tweet about the 2018 Academy Awards: 'Lowest rated Oscars in HISTORY. Problem is, we don't have Stars anymoreexcept your President (just kidding, of course)!' What has yet to be seen is whether these communication strategies will continue to be effective for Trump as he attempts to maintain his coalition during future U.S. elections or whether emerging political candidates on the international stage will be able to replicate Trump's success in attracting followers and crafting a political brand on social media.

\section{Notes}

1. http://graphics.wsj.com/clinton-trump-twitter/.

2. http://graphics.wsj.com/clinton-trump-twitter/.

\section{Disclosure statement}

Q6 No potential conflict of interest was reported by the authors.

\section{Notes on contributors}

Andrea McDonnell is associate professor of Media Studies at Emmanuel College. Her work emphasizes the intersection of media technologies, audiences, and everyday life. She is the author of Reading Celebrity Gossip Magazines (Polity Press, 2014) and her new book, Celebrity: A History of Fame, co-authored with Susan Douglas (University of Michigan), is forthcoming with NYU Press. She tweets at @doctordreuh.

Mark Wheeler is professor of Political Communications at London Metropolitan University. He authored several books including Celebrity Politics: Image and Identity in Contemporary Political Communications (Polity Press, 2013) and Public Spheres and Mediated Social Networks in the Western Context and Beyond (Palgrave Macmillan, 2016, with Petros losifidis). He has published a range of articles in peer-reviewed journals and chapters in edited books. He is a Visiting Fellow at the Media and Communications Department at the London School of Economics. 


\section{References}

Q7 Goffman, E., 1959. The presentation of self in everyday life. New York, NY: Anchor Books.

Horton, D. and Richard Wohl, R., 1956. Mass communication and para-social interaction: observa- 165 tions on intimacy at a distance. Psychiatry, 19 (3), 215-229.

Marsh, D., Hart, P., and Tindall, K., 2010. Celebrity politics: the politics of the late modernity? Political Studies Review, 8 (3), 322-340.

Marshall, P.D., 1997. Celebrity and power: fame in contemporary culture. Minneapolis, MN: University of Minnesota Press.

Meyrowitz, J., 1986. No sense of place: the impact of electronic media on social behavior. Oxford: Oxford University Press.

Street, J., 2003. The celebrity politician: political style and popular culture. In: J. Corner and J. Pels,

Q8 eds. The media and the restyling of politics. London: Sage.

Street, J., 2004. Celebrity politicians: popular culture and political representation. The british journal of politics and international relations, 6 (4), 435-452.

Street, J., 2010. Mass media, politics and democracy. Basingstoke: Palgrave Macmillan.

Weber, M., 1998. The sociology of charismatic authority. In: H. Gerth and C.W. Mills, eds. From Max

Q9 Weber: essays in sociology. New York: Oxford University Press.

Q10 Wheeler, M., 2013. Celebrity politics. London: Polity Press.

Wheeler, M., 2014. The mediatization of celebrity politics through the social media. International Journal of Digital Television, 5 (3), 221-236. 